\title{
Antecedents and Efficacy of Design-driven Innovation Based on the Perspective of Knowledge Flow
}

\author{
Quan-Xiang Xue ${ }^{1}, \mathrm{Hu} \mathrm{Xu}^{2, *}$, Xi-Yuan Yang ${ }^{2}$, Yao $\mathrm{Ma}^{2}$, Tian-Qi Zheng ${ }^{2}$, Xiu-Ya,Shi², \\ Wen-Hui Kang ${ }^{2}$ \\ ${ }^{1}$ Business school Hohai University, Nanjing, Jiangsu, China \\ ${ }^{2}$ School of Economics and Management, Jiangsu University of Science and Technology, Zhenjiang, Jiangsu, China \\ *Corresponding author.Email:2692886415@qq.com
}

\begin{abstract}
Based on the perspective of knowledge flow, this paper systematically explores the antecedents and effects of design-driven innovation. Based on the questionnaire survey of 602 senior managers in Jiangsu, Zhejiang and Shanghai, the empirical test draws the following conclusions: Organizational critical thinking and innovation openness both positively affect design-driven innovation; Design-driven innovation positively affects firm innovation performance, and plays a partial mediating role between organizational critical thinking and firm innovation performance, and between innovation openness and firm innovation performance. Knowledge integration ability has a positive moderating effect on the relationship between organizational critical thinking and design-driven innovation, as well as the relationship between innovation openness and design-driven innovation.
\end{abstract}

Keywords: organizational critical thinking, innovation openness, design-driven innovation, knowledge integration ability, firm innovation performance

\section{INTRODUCTION}

Innovation is an important way and fundamental guarantee for enterprises to gain competitive advantages and seek rapid development. With the increasingly prominent role of design in organizational innovation, design-driven innovation has attracted extensive attention in the academic community[1]. Verganti first proposed the concept of design-driven innovation, and defined it as an innovation in which the novelty of the information conveyed by a product and its design language exceeds the novelty of the product's function and technology[2]. In other words, different from traditional technology and market innovation, design-driven innovation is a radical innovation in product language (meaning), emphasizing the shaping of brand-new product meaning and connotation according to future social and cultural development trends[2].

The core of design-driven innovation lies in the continuous direct or indirect communication and interpretation of the internal and external network entities of the organization, to realize the development, transmission and interaction of social culture and technical knowledge, and ultimately create new product meaning[3]. It can be seen that the acquisition, integration and utilization of relevant social culture and technical knowledge play a decisive role in promoting design-driven innovation of enterprises and achieving innovation performance. In view of this, this article will start from the perspective of knowledge flow and systematically interpret the internal process of enterprise knowledge acquisition to enhance design-driven innovation and transform it into innovation performance.

Although previous studies have confirmed the significance and value of knowledge acquisition from the external network of the enterprise for design-driven innovation[4][5], design-driven innovation involves both internal and external (network) aspects of the organization, and both are indispensable[6]. Internally, the organization encourages employees to use questioning eyes to critically think about current products, to realize knowledge creation and the construction of new product visions, and to promote knowledge collisions between employees and rational thinking and repeated demonstrations of new visions by building communication channels. In this way, the 
feasibility of the new product vision and design plan is improved. Externally, enterprises can establish extensive and close connections with external network members by improving their openness to innovation. This provides enterprises with information and knowledge about future social and cultural development, thereby continuously promote design-driven innovation. In view of this, this article intends to select the two antecedent variables of organizational critical thinking and innovation openness to comprehensively examine the antecedents of design-driven innovation from the perspective of internal and external knowledge acquisition of the organization.

Second, a small number of sporadic studies have shown that if the diversified knowledge in the network cannot be effectively integrated, it will lead to design confusion, which may hinder the generation of design-driven innovation capabilities[6]. In companies with high knowledge integration capabilities, companies can quickly and orderly sort, integrate and reconstruct the massive and diversified internal and external knowledge acquired, so as to maximize the value of internal and external knowledge acquired through organizational critical thinking and innovative openness, In other words, at this time, organizational critical thinking and innovation openness will have a more significant effect on promoting design-driven innovation. In view of this, this article intends to select knowledge integration ability as a moderating variable to examine the impact of organizational critical thinking and innovation openness on the boundary utility of design-driven innovation.

In summary, in order to make up for the deficiencies of previous studies, based on the perspective of knowledge flow, this article will bring critical thinking/innovation openness (knowledge acquisition), knowledge integration capabilities (knowledge integration), design-driven innovation (knowledge utilization), and corporate innovation performance (Knowledge Achievements) into the same research framework, not only theoretically enriches the design-driven innovation theory, but also provides practical guidance and assistance for enterprises to improve design-driven innovation capabilities and ultimately improve innovation performance by acquiring and integrating internal and external knowledge.

\section{LITERATURE REVIEW RESEARCH HYPOTHESIS}

\subsection{Organizational Critical Thinking and Design-driven Innovation}

Critical thinking is an individual's way of thinking and ability to boldly question, carefully think and argue, and make rational judgments[7]. This article considers organizational critical thinking as a series of formal or informal organizational norms and practices that encourage and support employees to question the status quo, analyze problems, carefully verify, and make clear judgments.

First, organizations with high critical thinking encourage and support employees to question the status quo and analyze problems, creating a working environment for employees to question boldly and carefully verify verification. In this environment, employees use questioning eyes to critically think about current products, put forward novel insights on future social and cultural development trends, give new connotations and meanings to products[6], and promote design-driven innovation. Studies have confirmed that critical thinking positively affects the innovative activities of organization members[8]. Based on this, this research proposes the following hypotheses:

H1: Organizational critical thinking positively influences design-driven innovation.

\subsection{Innovation Openness and Design-driven Innovation}

Innovation openness including the breadth and depth of openness. The breadth of openness refers to the scale and scope of enterprise cooperation. The depth of openness refers to the degree and frequency of mutual communication in the process of enterprise cooperation. Focusing on this article, the higher breadth of openness means that enterprises have established extensive contacts and cooperation with many network entities such as media, artists, and universities, so that enterprises can more easily and accurately identify the potential market demand and the development trend of social and cultural models[9], and provide resource support for creating design knowledge and building new product visions. Secondly, a higher depth of innovation and openness means that information exchange and interaction between enterprises are more frequent, and the design dialogue with external network innovation subjects is more adequate. This will enhance the enterprise's ability to identify and evaluate social culture and technical knowledge[10], Accordingly, the following assumptions are made:

$\mathrm{H} 2$ : Innovation openness has a positive impact on design-driven innovation.

\subsection{Design-driven Innovation and Firm Innovation Performance}

Enterprise innovation performance refers to the efficiency of enterprise innovation activities, the results created and the degree of contribution to economic benefits. Design-driven innovation can predict and explore the future social and cultural development trend, 
create novel and meaningful products, improve product differentiation, accelerate the process of new product development and market expansion, and thus improve the innovation performance of enterprises[9]. Relevant studies show that design-driven innovation can improve the innovation performance of enterprises [11]. Based on this, this study puts forward the following hypotheses:

H3: Design-driven innovation has a positive impact on enterprise innovation performance.

\subsection{The Intermediary Effect of Design-driven Innovation}

To sum up, organizations with high critical thinking and high degree of innovation openness can improve design-driven innovation capabilities. Through design innovation, product differentiation and uniqueness can be improved, new product development and market expansion can be accelerated, so firm innovation performance can be enhanced. Accordingly, the following assumptions are made:

H4a: Design-driven innovation exerts an intermediary effect between organizational critical thinking and firm innovation performance.

H4b: Design-driven innovation exerts an intermediary effect between innovation openness and firm innovation performance.

\subsection{The Moderating Effect of Knowledge Integration Ability}

Knowledge integration ability refers to the dynamic ability of firms to screen, deconstruct, reorganize and innovate knowledge from the inside and outside. In this paper, whether the new vision and knowledge generated by the internal members with the help of organization critical thinking, or the knowledge acquired through the open innovation network, they have the characteristics of diversity, fragmentation, redundancy, silence and so on. When knowledge integration ability is high, firms will be able to identify, integrate and reconstruct the above-mentioned resources. Meanwhile, firms will maximize the use of knowledge acquired from the inside and outside to promote design-driven innovation, what is more, Organizational critical thinking and innovation openness will also have a more significant effect on promoting design-driven innovation. Accordingly, the following assumptions are proposed:

H5a: Knowledge integration ability positively moderates the positive relationship between organizational critical thinking and design-driven innovation.

H5b: Knowledge integration ability positively moderates the positive relationship between innovation openness and design-driven innovation.

Based on the above research assumptions, the theoretical model of this study is shown in Figure 1.

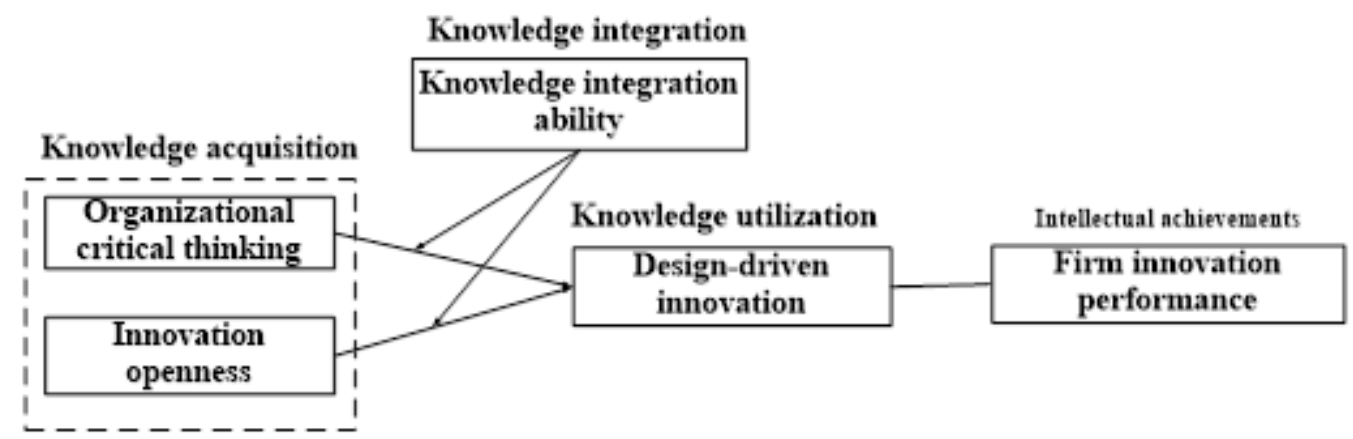

Figure 1. Theoretical model

\section{RESEARCH METHODS}

\subsection{Scale Design}

The scale of design-driven innovation is selected from the research of Xu Lei and Ni Jiajun[12]. There are 21 items in total. The scale of enterprise innovation performance is derived from the research of Zhang[13] and others. The scale has 5 items. The organizational critical thinking scale originated from the research of Jiang Jing and Yang Baiyin[8]. This article adjusts the subject of the original item to the word "employee". The scale has 5 items. The scale of innovation openness is derived from the research of Jiang Zhenyu[14] and others. The scale has a total of 8 items. The scale of knowledge integration ability is derived from the research of Ke Jianglin[15] and others. The scale has 3 items, representative items.

Drawing lessons from previous studies[16], this paper selects firm size, firm age, firm nature and industry as the control variables. In terms of item measurement, all variables use Likert 5-point scale (except control variables).

\subsection{Data Collection}

This study takes enterprises in the Jiangsu, Zhejiang and Shanghai as the research objects, and uses field surveys and mailing paper questionnaires for data collection. The respondents are middle and senior 
managers of enterprises. A total of 700 questionnaires were distributed and 618 were actually recovered. After eliminating invalid questionnaires such as missing questionnaires and inconsistencies, a total of 602 valid questionnaires were obtained, with an effective recovery rate of $86 \%$. In the effective sample, $37.9 \%$ of enterprises have more than 500 employees. $72.1 \%$ of enterprises with more than 5 years of age. It covers state-owned, private and joint venture enterprises, and involves many industries such as electronic communication and machinery manufacturing.

\section{DATA ANALYSIS AND RESULTS}

\subsection{Data Quality Analysis}

The $\alpha$ value of each variable ranges from 0.709 to 0.903 ( $>0.7)$, and the $\mathrm{CR}$ value ranges from 0.708 to 0.831 ( $>0.6$ ), indicating a high internal consistency and combination reliability. The AVE value of each variable ranged from 0.509 to 0.721 (all greater than 0.5 ), indicating good convergent validity. The square root of AVE of each variable is significantly larger than the correlation coefficient of this variable and other variables, indicating that it has good discrimination validity. In addition, the fitting effect of the five-factor model is the most ideal $(\chi 2 / \mathrm{df}=2.857$, $\mathrm{RMSEA}=0.057$, $\mathrm{GFI}=0.954$, NFI $=0.992$, TLI $=0.912$, IFI $=0.937$, $\mathrm{CFI}=0.935$ ), again showing that it has a good structural effect degree.

\subsection{Correlation Analysis}

Organizational critical thinking $(\mathrm{r}=0.548, \mathrm{p}<0.01)$, innovation openness $(\mathrm{r}=0.595, \quad \mathrm{p}<0.01), \quad$ and design-driven innovation $(\mathrm{r}=0.655, \mathrm{p}<0.01)$ have a significant positive effect on enterprise innovation performance. Organizational critical thinking $(\mathrm{r}=0.541$, $\mathrm{p}<0.01)$ and innovation openness $(\mathrm{r}=0.524, \mathrm{p}<0.01)$ are significantly correlated with design-driven innovation. There is also significant correlation between knowledge integration ability and organizational critical thinking $(\mathrm{r}=0.448, \quad \mathrm{p}<0.01)$, innovation openness $(\mathrm{r}=0.424$, $\mathrm{p}<0.01)$, and design-driven innovation $(\mathrm{r}=0.437$, $\mathrm{p}<0.01$ ), laid the foundation for subsequent hypothesis testing.

\subsection{Hypothetical Test}

\subsubsection{Direct Effect Test}

As shown in Table 1, M1 tests the influence of control variables on design-driven innovation. As shown in $\mathrm{M} 2$, organizational critical thinking has a significant positive impact on design-driven innovation $(\beta=0.649$, $\mathrm{p}<0.001$ ), and $\mathrm{H} 1$ is verified. As shown in M3, innovation openness has a significant positive effect on design-driven innovation $(\beta=0.720, p<0.001)$, and $\mathrm{H} 2$ is verified. M4 tests the influence of control variables on firm innovation performance. As shown in M5, design-driven innovation has a significant positive impact on firm innovation performance $(\beta=0.642$, $\mathrm{p}<0.001)$, and $\mathrm{H} 3$ is verified.

\subsubsection{Mediation Test}

As shown in Table 1, M6 adds organizational critical thinking to M4, and the results show that organizational critical thinking has a significant positive impact on corporate innovation performance $(\beta=0.477, p<0.001)$. When design-driven innovation is added to the M8 regression equation, design-driven innovation has a significant positive impact on enterprise innovation performance $\quad(\beta=0.525, \quad \mathrm{p}<0.001)$; although the relationship between organizational critical thinking and enterprise innovation performance is significant, Obviously weakened $(\beta=0.136, p<0.01)$, indicating that design-driven innovation plays a part of the mediating role between organizational critical thinking and corporate innovation performance, that is, hypothesis $\mathrm{H} 4 \mathrm{a}$ is verified.

M7 adds innovation openness to M4, and the results show that innovation openness has a significant positive impact on enterprise innovation performance $(\beta=0.584$, $\mathrm{p}<0.001)$. When design-driven innovation is added to the M9 regression equation, design-driven innovation has a significant positive impact on enterprise innovation performance $(\beta=0.462, \quad \mathrm{p}<0.001)$; the relationship between innovation openness and enterprise innovation performance is significant but obvious Weakness $\quad(\beta=0.251, \quad p<0.001)$, indicating that design-driven innovation plays a partial mediating role between innovation openness and enterprise innovation performance, that is, hypothesis $\mathrm{H} 4 \mathrm{~b}$ is verified.

Table 1 Analysis of direct effect and intermediary effect

\begin{tabular}{|c|c|c|c|c|c|c|c|c|c|}
\hline \multirow[t]{2}{*}{ Variables } & \multicolumn{3}{|c|}{$\begin{array}{c}\text { Mediating variables: } \\
\text { design-driven innovation }\end{array}$} & \multicolumn{6}{|c|}{ Dependent variable: corporate innovation performance } \\
\hline & M1 & M2 & M3 & M4 & M5 & M6 & M7 & M8 & M9 \\
\hline $\begin{array}{l}\text { Control } \\
\text { variables }\end{array}$ & & & & & & & & & \\
\hline
\end{tabular}




\begin{tabular}{|c|c|c|c|c|c|c|c|c|c|}
\hline Scale of firm & 0.021 & 0.010 & 0.030 & -0.007 & -0.021 & -0.015 & 0.000 & -0.020 & -0.014 \\
\hline Age of firm & 0.106 & 0.106 & 0.038 & 0.111 & 0.043 & 0.111 & 0.055 & 0.055 & 0.038 \\
\hline Firm nature & $\begin{array}{c}-0.05 \\
5\end{array}$ & -0.029 & 0.002 & -0.022 & -0.014 & -0.003 & 0.024 & 0.013 & 0.023 \\
\hline Industry & $\begin{array}{c}-0.02 \\
7\end{array}$ & -0.004 & 0.009 & -0.046 & -0.029 & -0.030 & -0.017 & -0.027 & -0.021 \\
\hline $\begin{array}{l}\text { Independent } \\
\text { variables }\end{array}$ & & & & & & & & & \\
\hline $\begin{array}{l}\text { Organizational } \\
\text { critical thinking }\end{array}$ & & $0.649 * * \star$ & & & & $0.477^{\star \star \star}$ & & $0.136^{\star *}$ & \\
\hline $\begin{array}{l}\text { Innovative } \\
\text { Openness } \\
\text { Mediating } \\
\text { variables }\end{array}$ & & & $0.720^{\star \star \star}$ & & & & $0.584^{\star \star *}$ & & $0.251^{\star * *}$ \\
\hline $\begin{array}{c}\text { Design-driven } \\
\text { innovation } \\
\text { Statistical } \\
\text { changes }\end{array}$ & & & & & $0.642^{* * \star}$ & & & $0.525^{\star \star *}$ & $0.462^{\star \star *}$ \\
\hline $\mathrm{R}^{2}$ & 0.030 & 0.571 & 0.530 & 0.031 & 0.436 & 0.327 & 0.364 & 0.446 & 0.466 \\
\hline $\begin{array}{c}\mathrm{R} \text { of } \\
\text { amendments }^{2}\end{array}$ & 0.023 & 0.567 & 0.526 & 0.024 & 0.431 & 0.321 & 0.359 & 0.441 & 0.460 \\
\hline$\Delta \mathrm{R}^{2}$ & 0.030 & 0.541 & 0.500 & 0.031 & 0.405 & 0.296 & 0.333 & 0.120 & 0.102 \\
\hline F value & 4.570 & 158.552 & 134.457 & 4.717 & $\begin{array}{c}92.010 * * \\
*\end{array}$ & 57.804 & 68.191 & 79.937 & 86.367 \\
\hline$\Delta \mathrm{F}$ & $\begin{array}{c}4.570^{*} \\
*\end{array}$ & $751.499 \star \star *$ & $634.603^{* * *}$ & $4.717^{\star \star *}$ & 427.692 & $261.905^{\star \star \star}$ & $312.249 * * \star$ & $128.682^{\star \star *}$ & $113.111^{\star * \star}$ \\
\hline
\end{tabular}

Note: 1 . the regression coefficient is unstandardized regression coefficient $; 2 * \mathrm{p}<0.05, * * \mathrm{p}<0.01, * * * \mathrm{p}<0.001$.

\subsubsection{Moderation Test}

As shown in Table 2, based on M10, M11 adds knowledge integration ability, the results show that knowledge integration ability $(\beta=0.055, \quad \mathrm{p}<0.05)$ significantly positively affects design-driven innovation. Based on M11, M12 adds the interactions terms
Organizational critical thinking $\times$ Knowledge integration ability $(\beta=0.048, p<0.05)$ and Innovation openness $\times$ Knowledge integration ability $(\beta=0.025$, $\mathrm{p}<0.05)$. The results show that the coefficients of each interaction term are positive and significant. so the H5a and $\mathrm{H} 5 \mathrm{~b}$ are verified.

Table 2 Regression analysis results of moderating effects

\begin{tabular}{|c|c|c|c|c|}
\hline \multirow{2}{*}{ Variables } & \multicolumn{4}{|c|}{ Design-driven innovation } \\
\hline & M1 & M 10 & M 11 & M 12 \\
\hline \multicolumn{5}{|l|}{ Control variables } \\
\hline Scale of firm & 0.021 & 0.019 & 0.023 & 0.023 \\
\hline Age of firm & 0.106 & 0.069 & 0.063 & 0.063 \\
\hline Firm nature & -0.055 & -0.007 & -0.009 & -0.008 \\
\hline Industry & -0.027 & 0.007 & 0.010 & 0.009 \\
\hline \multicolumn{5}{|l|}{ Independent variables } \\
\hline Organizational critical thinking & & $0.418^{* * *}$ & $0.400 * \star \star$ & $0.398^{* * *}$ \\
\hline
\end{tabular}




\begin{tabular}{|c|c|c|c|c|}
\hline Innovative Openness & & $0.394^{* \star *}$ & $0.381^{\star \star \star}$ & $0.387^{\star \star \star}$ \\
\hline Knowledge integration capacity & & & $0.055^{*}$ & $0.045^{\star}$ \\
\hline \multicolumn{5}{|l|}{ Interactions terms } \\
\hline $\begin{array}{l}\text { Organizational critical thinking } \times \text { Knowledge } \\
\text { integration ability }\end{array}$ & \multicolumn{3}{|c|}{ integration ability } & $0.048^{*}$ \\
\hline Innovation openness $\times$ Knowledge integration ability & & & & $0.025^{*}$ \\
\hline \multicolumn{5}{|l|}{ Statistical changes } \\
\hline $\mathrm{R}^{2}$ & 0.030 & 0.652 & 0.655 & 0.656 \\
\hline R of amendments ${ }^{2}$ & 0.023 & 0.648 & 0.651 & 0.651 \\
\hline$\Delta R^{2}$ & 0.030 & 0.622 & 0.003 & 0.001 \\
\hline F value & $4.570^{\star \star}$ & $185.711^{\star \star \star}$ & $161.112^{\star * \star}$ & $125.342^{* * *}$ \\
\hline$\Delta \mathrm{F}$ & 4.570 & 531.742 & 5.357 & 0.705 \\
\hline
\end{tabular}

Note:1. the regression coefficient is unstandardized regression coefficient $; 2 * \mathrm{p}<0.05, * * \mathrm{p}<0.01, * * * \mathrm{p}<0.001$.

\section{RESEARCH CONCLUSIONS}

This paper starts from the perspective of knowledge flow and finds through empirical testing:

(1)Organizational critical thinking and innovation openness both positively affect design-driven innovation. This shows that the critical thinking of 'Boldly assume, carefully verify' created and the extensive and close connections established with external network subjects by organizations can promote design-driven innovation. (2) Design-driven innovation plays a partial intermediary role between organizational critical thinking and firm innovation performance, innovation openness and enterprise innovation performance respectively. This shows that the use of internal and external network resources by firms can improve the ability of design innovation, thereby enhancing firm innovation performance. (3) Knowledge integration ability plays a positive moderating role between organizational critical thinking and design-driven innovation, innovation openness and design-driven innovation respectively. This shows that the stronger the ability of firms to identify key information and integrate diversified and scattered knowledge, the more the value of knowledge acquisition can be brought into play.

\section{REFERENCES}

[1] Roberto V,"The third type of Innovation: how design-driven innovation creates new rules of competition", China Renmin University Press, 2014.

[2] Roberto V,"Design as brokering of languages: Innovation strategies in Italian firms", Design Management Journal, 2003, 13(3): 34-42.

[3] Roberto V."Design, meanings, and radical innovation: A metamodel and a research agenda", Journal of Product Innovation Management, 2008, 25(5): 436-456.
[4] Menguc B, Auh S, Yannopoulos P. "Customer and supplier involvement in design: The moderating role of incremental and radical innovation capability", Journal of Product Innovation Management, 2014, 31(2): 313-328.

[5] Xu Lei.,"The Evolution of Zheshang Business Model from the Perspective of Design-Driven Innovation: A Case Study of WENSLI", Business Economics and Management, 2015(1): 55-63.

[6] Chen Xuesong, Chen Jin,"A Review of Latest Development of Design-driven Innovation Theory", Foreign economy and management, 2016, 38(11): 45-57.

[7] Facione N C, Facione P A.,"Externalizing the critical thinking in knowledge development and clinical judgment", Nursing Outlook, 1996, 44(3): $129-136$.

[8] Jiang Jing, Yang Baiyin.,"Critical Thinking, Creative Self-efficacy and Employee Creativity: Weakening Effect of Leader-member Exchange in Chinese Context", Nankai Management Review, 2014, 17(2): 117-128.

[9] Chen Guodong, Chen Qi.,“ Re-examination of Design-driven Innovation: The Perspective of Connotation and Growth Mechanism", Economic System Reform, 2012(1): 127-131.

[10] Xu Qian.,"Research on the Influence Mechanism of Innovation Openness and Knowledge Absorptive Capacity on Enterprise Innovation Performance-Based on the Perspective of Environmental Dynamics", Forecast, 2020, 39(5): 9-15.

[11] Henderson R M, Clark K B.," Architectural innovation: The reconfiguration of existing product technologies and the failure of established firms", 
Administrative Science Quarterly, 1990, 35(1): 9-30.

[12] $\mathrm{Xu}$ Lei, Ni Jiajun.,"How does network heterogeneity improve innovation performance? An empirical analysis from design-driven innovation perspective", Science of Science, 2019, 37(7): 1334-1344.

[13] Zhang Y, Li H.,"Innovation search of new ventures in a technology cluster: The role of ties with service intermediaries", Strategic Management Journal, 2010, 31(1): 88-109.
[14] Jiang Zhenyu, Wang Zongjun, Pan Wenyan.,"The New Path of the Effect of Openness on Innovative Capacity:A Moderated Mediation Model", Management Review, 2019, 31(10): 85-98.

[15] Ke Jianglin, Sun Jianmin, Shi Jintao, et al., “ An Empirical Study on the Relationship between Social Capital and Team Effectiveness of Enterprise R\&D Teams-Taking knowledge sharing and knowledge integration as mediating variables”, Management World, 2007(3): 89-101.

[16] Chen Yufen, Chen Jin. ,"The influence of openness to innovation performance", Studies in Science of Science, 2008(2): 419-426. 